\title{
Luis Salas Almela, La más Callada ReVOluCión. CONFLICTOS ADUANEROS, NOBLEZA Y CORONA EN Castilla (1450-1590), Madrid, Editorial SíleX, 2020, 302 PÁGS. ISBN: 978-84-7737-553-I
}

\author{
José Manuel Triano Milán \\ Universidad del País Vasco/ Euskal Herriko Unibertsitatea
}

En su Manifiesto por la Historia los profesores Jo Guldi y David Armitage propugnaban hace unos años la necesidad de retomar los análisis históricos de larga duración, superando el cortoplacismo que parece haberse instalado en nuestra profesión. A pesar de este y otros alegatos, lo cierto es que siguen siendo muy pocos los investigadores que se atreven a trascender los estrechos márgenes que marcan unas pocas décadas de estudio y muchos menos los que rompen con los límites artificiales que imponen los períodos históricos. El trabajo que aquí presentamos es, precisamente, una de esas raras excepciones. En él, un modernista se atreve a realizar una investigación que, hundiendo sus raíces en pleno período bajomedieval, se prolonga durante más de una centuria.

El tema del libro merece todo este esfuerzo. La construcción del Estado y el papel jugado por la nobleza en dicho proceso es uno de los debates historiográficos más candentes de los últimos años y los importantes avances realizados por la investigación abocan a la necesidad de una revisión en profundidad de esta cuestión. Luis Salas no solo se atreve a abordar dicha revisión de manera crítica, sino que aporta su visión de conjunto a través del análisis de un aspecto central hasta ahora un tanto ignorado: la participación de la nobleza en la fiscalidad sobre el comercio externo de la Corona. Pero, lejos de los tradicionales estudios sobre aspectos hacendísticos a los que estamos acostumbrados, el libro aquí presentado huye de la especialización y el gusto por el detalle contable, eliminando la aridez y la oscuridad que este tipo de cuestiones suelen presentar para la mayoría de los lectores. En su lugar, utiliza la abundante información que le permite esta perspectiva de estudio para pintar un complejo e interesante cuadro sobre las relaciones entre la Corona y las principales casas nobiliarias en Castilla. El resultado es un discurso que rompe con la idea de la construcción del Estado en Europa desde una perspectiva unidireccional centrada exclusivamente en el paulatino reforzamiento de la autoridad monárquica, para señalar el papel fundamental de la nobleza en este proceso y cómo se fueron transformando las complejas relaciones entre este estamento y el trono. Pese a su amplia perspectiva, esta monografía no pierde de vista la investigación de base. Todo el libro se sostiene sobre una equilibrada mezcla de análisis concretos y 
reflexiones generales, demostrando que unos no son posibles sin los otros. Así, las sugestivas páginas que dan forma a la introducción y a las conclusiones son producto de la decantación de tres estudios de caso sobre grandes casas señoriales que el autor ha venido trabajando con ahínco durante los últimos años. Los Velasco, los Medinaceli y los Medina Sidonia ocupan la mayor parte de las trescientas páginas del libro, ejemplificando ese proceso histórico antes mencionado, pero también mostrando algunos particularismos sumamente interesantes.

El primer apartado, dedicado a los Velasco es, en nuestra opinión, la parte más atractiva de la monografía. Más allá de la manida referencia a los intereses del linaje como un concepto limitado y difuso, Luis Salas nos presenta esta realidad en toda su extensión. La descripción de la compleja red de intereses creados por esta familia a lo largo $\mathrm{y}$ ancho del norte de la Corona nos permite comprender cuáles eran sus principales objetivos políticos y económicos y los mecanismos desarrollados para llevarlos a cabo, al tiempo que permite explicar buena parte de la evolución histórica de todo este espacio. Deshacer y analizar en esta compleja madeja de intereses cruzados no sería posible si el autor no contara con una línea argumental sólida, encontrándola en el control que los Velasco tuvieron sobre los diezmos de la mar. Esta carga fiscal, que gravaba el conjunto del comercio marítimo de los puertos del norte, fue cedido a don Pedro Fernández de Velasco por parte de Enrique IV. A partir de entonces, los Velasco no solo contaron con una importante fuente de recursos, sino que también dispusieron de un magnífico instrumento para aglutinar a las ramas secundarias del linaje gracias a la gestión de la renta, un medio para influir sobre núcleos urbanos tan importantes como Burgos o Bilbao y una importante baza para negociar con la Corona.

El siguiente apartado, dedicado al estudio de los almojarifazgos andaluces se encuentra dividido en el análisis de dos de las principales casas de la región: los Medinaceli y los Medina Sidonia. A través del control de la renta desde el Puerto de Santa María se analiza el papel jugado por los Medinaceli en la expansión comercial de la Baja Andalucía, al tiempo que se observan de cerca los conflictos generados con otros poderes tan representativos de la región como la propia ciudad de Sevilla. En este contexto, se describe cómo se articularon las emergentes relaciones con América y el establecimiento de un sistema de comunicación e intercambio que acabó tomando forma mediante la célebre Carrera de Indias. Por su parte, en el apartado dedicado a los Medina Sidonia se refleja claramente que este ha sido uno de los ámbitos de estudio predilectos del autor y el objeto de su tesis doctoral. Su amplio conocimiento sobre la cuestión le permite trazar un complejo panorama en el que se observa cómo se integra el dominio de sus amplios señoríos con el control de unas rentas sobre el comercio exterior que les permitió ejercer una poderosa influencia en toda la Baja Andalucía y aún más allá. En este sentido, el papel clave del dominio sobre Melilla y la importante política exterior desplegada por esta casa en paralelo a la desarrollada por la Corona resulta un tema trascendental que, apenas esbozado aquí, merecería un estudio monográfico.

El proceso de reversión de los almojarifazgos a la Corona a partir del reinado de Felipe II generó fuertes tensiones con estas casas nobiliarias y marcó el tono de las relaciones 
entre estos agentes políticos. El impacto de esta medida tuvo un éxito desigual -los Medina Sidonia lograron mantener la renta hasta el siglo XVIII, mientras que los Medinaceli se vieron privados de ella-, aunque ambos linajes hubieron de replantear sus estrategias y sacar partido a las posibilidades que la nueva situación les planteaba. Una recomposición de su papel que va más allá del plano meramente fiscal y evidencia el nuevo marco de relaciones que se estaba definiendo en el conjunto del reino.

Todo este panorama nos muestra cómo la cesión de la gestión de esta fiscalidad sobre el comercio exterior de la Corona a la nobleza, más que una anomalía o la pervivencia de elementos "feudalizantes" dentro de un estado "moderno", son el resultado lógico del papel ejercido por la aristocracia en la estructura política que estaba tomando forma y que esta ayudó a construir. Una realidad sumamente compleja, que quizás un mayor manejo de datos fiscales -aún a riesgo de que el discurso perdiera un tanto de ese carácter asequible que reseñábamos anteriormente-, ayudaría a entender mejor. En este sentido, se echa un tanto en falta algún cuadro a lo largo del texto o a modo de anexo que permita establecer las sumas manejadas en los ingresos aquí estudiados. Así mismo, el proceso de revisión y reversión de todas estas rentas a la Real Hacienda en tiempos de Felipe II quizás hubiera merecido una contextualización más desarrollada, permitiendo a los lectores no especializados una mejor comprensión de una etapa de complejas transformaciones hacendísticas.

Pese a estas pequeñas limitaciones, el resultado de todo este trabajo es sumamente sugestivo. No solo se nos presenta una importante carga de erudición sobre aspectos concretos del funcionamiento de tres grandes linajes castellanos, sino que se realiza un aporte original a uno de los debates historiográficos más importantes de las últimas décadas. Una interpretación que, aunque pueda ser discutida en alguno de sus puntos -sin ir más lejos, el autor de esta reseña difiere en algunas cuestiones-, se encuentra sumamente bien argumentada y sustentada en ejemplos concretos. Todo ello nos recuerda que, pese a su dificultad, los historiadores no pueden huir de su labor a la hora de aportar interpretaciones globales y ampliar el debate historiográfico con nuevas ideas. Ideas que nunca deben quedar constreñidas por esas periodizaciones de carácter artificial que nosotros mismos nos hemos impuesto. 